\title{
Molecular Species in the Protein Body II (PB-II) of Developing Rice Endosperm
}

\author{
Toshio Sugimoto, Kunisuke TANAKA ${ }^{*, \dagger}$ and Zenzaburo KasaI ${ }^{* *}$ \\ National Food Research Institute. Ministry of Agriculture, \\ Forestry and Fisheries, Ibaraki 305, Japan \\ * Department of Biochemistry, College of Agriculture, \\ Kyoto Prefectural University, Kyoto 606, Japan \\ ** Plant Nutrition Laboratory, College of Agricultural Chemistry, \\ Kinki University, Osaka 577, Japan
}

Received May 13, 1986

\begin{abstract}
The molecular weight and subunit composition of glutelin, the major storage protein of rice, in the major type of protein bodies of developing rice seeds was examined by gradient and twodimensional sodium dodecyl sulfate polyacrylamide gel electrophoresis (SDS-PAGE). Glutelin in the protein body was the assembled from heterogeneous subunits, and the molecular weights were estimated to be $64,140,240,320,380$, and $500 \mathrm{k}$ by gradient SDS-PAGE. High molecular weight proteins (larger than 2,000 k) were also observed.

The two-dimensional SDS-PAGE under reduced conditions showed, that the glutelin in the protein body was composed of two groups of polypeptides, $22 \sim 23$ and $37 \sim 39 \mathrm{k}$, bound by disulfide linkages.
\end{abstract}

Rice glutelin, the major storage protein of rice, has been reported to be a homogeneous protein with a molecular weight of about $2,000 \mathrm{k},{ }^{1)}$ with three different sized subunits. Their molecular weights have been reported to be 20,34 , and $43 \mathrm{k}$ by Swai et al. ${ }^{2,3)}$ and 17,25 , and $39 \mathrm{k}$ by Juliano and Boulter. $\left.{ }^{4}\right)$

Gultelin is deposited in the protein bodies of starchy endosperm, ${ }^{5,6)}$ where there are two types of protein bodies. ${ }^{7}$ One of them, which has no concentric strata (PB-II) contains only a few kinds of polypeptides such as $22 \sim 23$ and $37 \sim 39 \mathrm{kmol}$. wt. polypeptides judging from the profile on SDS-PAGE. By the solubity fractionation of proteins in PB-II, $22 \sim 23$ and $37 \sim 39 \mathrm{k}$ polypeptides were observed in the glutelin fraction, and the $26 \mathrm{k}$ polypeptide in the globulin fraction, respectively.

We examined the structure of the glutelin in the PB-II protein body, using gradient- and two-dimensional SDS-PAGE.

\footnotetext{
$\dagger$ To whom correspondence should be addressed.
}

\section{MATERIALS AND METHODS}

Preparation of PB-II from developing endosperm of rice. Protein bodies were isolated from developing rice endosperm (Oryza sativa, Japonica cv. Koshihikari) as described previously using sucrose density gradient centrifugation. ${ }^{7)}$

Concave gradient SDS-PAGE of the proteins in PB-II. Fifty microliters of PB-II fraction (absorbance at 280 $\mathrm{nm}$ referenced at $340 \mathrm{~nm}$ was 2.0 ) of the sucrose density gradient (SDG) centrifugation was mixed with $50 \mu \mathrm{l}$ of buffer A ( $4 \%$ sodium dodecyl sulfate (SDS), $8 \mathrm{~m}$ urea, and $10 \mathrm{~mm}$ phosphate buffer with or without $50 \mathrm{~mm} \mathrm{~N}$ ethyl maleimide (NEM)) and was incubated for $8 \mathrm{hr}$ at $90^{\circ} \mathrm{C}$ to solubilize it. Fifty microliters of the solution was put on a polyacrylamide concave gradient gel $(4 \sim 30 \%)$ and was electrophoresed at a constant voltage or $70 \mathrm{~V}$ for $20 \mathrm{~min}$ then $100 \mathrm{~V}$ for $40 \mathrm{hr}$ at room temperature. After the electrophoresis, the gel was stained with Coomassie Brilliant Blue R-250 in 7\% acetic acid and $50 \%$ isopropanol for $1 \mathrm{hr}$ and destained in $7 \%$ acetic acid. Each line of the gel was scanned at $590 \mathrm{~nm}$ using a reference wavelength at $750 \mathrm{~nm}$ on a Shimadzudual-wavelength chromatoscanner model CS-910. Molecular weights of the proteins were calibrated by the protein standard markers (Fig. 2). 
Two-dimensional SDS-PAGE of the proteins in the PBII. Protein bodies were precipitated by centrifugation at $3,500 \times g$ for $20 \mathrm{~min}$ after $200 \mu \mathrm{l}$ of the PB-II fraction prepared by the SDG centrifugation was diluted with an excess of $0.3 \mathrm{~m}$ sucrose in $10 \mathrm{~mm}$ pH 7.5 Tris- $\mathrm{HCl}$. Samples for the PAGE were prepared by the same method except that the SH-masking reagent, $10 \mathrm{~mm}$ iodoacetic acid at the final concentration, was used. For the SDS-PAGE, $50 \mu \mathrm{l}$ of the solution was put on a $6 \%$ disc gel $(c=5 \%$, $5 \mathrm{~mm} \times 13 \mathrm{~cm}$ ) and was electrophoresed until the tracking dye, bromphenol blue (B.P.B), migrated to the end of the disc at $2 \mathrm{~mA} /$ tube. Then the disc gel was transferred onto a slab gel which was $12 \mathrm{~cm}$ wide and consisted of $1 \mathrm{~cm}$ of $1 \%$ agarose gel containing $1 \% 2$-mercaptoethanol, $1 \mathrm{~cm}$ of a stacking gel, and $10 \mathrm{~cm}$ of separating gel, from top to bottom. Agarose gel was buffered at the same conditions as for the stacking gel. The electrophoresis in the second direction and the staining of the gel were done as described above except that the electrophoresis was done until the marker pigment ran through the agarose gel at $50 \mathrm{~V}$.

\section{RESULTS}

\section{Polypeptides in PB-II and their polymeriza- tion}

The polypeptide composition in the developing PB-II, which is considered to be the accumulation site of rice glutelin, was examined (Fig. 1). The molecular weights of the individual bands were estimated by a calibration curve made by a concave SDS-PAGE as shown in Fig. 2. Analysis with NEM indicated a wide distribution of molecular weights of polypeptides, from very low ones (under our electrophoresis conditions, polypeptides smaller than $50 \mathrm{k} \mathrm{mol}$. wt. were in the gel front) to those larger than $500 \mathrm{k}$ mol.wt. (Fig. 1A). These polypeptides had mol. wt. of $64,90,130$, 240, 320, and 500 kilos forming discrete bands on the electrophoretogram. As shown in Fig. 1 , the $64,90,130$, and $240 \mathrm{k}$ bands were the major bands. Electrophoresis without NEM changed the pattern greatly (Fig. 1B). Under these conditions, the polypeptides with mol.wt. of 64 and $90 \mathrm{k}$ disappeared with a concomitant increase in the $240 \mathrm{k}$ polypeptide. The polypeptide with a mol. wt. of $130 \mathrm{k}$ also decreased. Polypeptides with a very high molecular weight increased at the origin of the gel. These results indicate the existence of polypeptide groups which are built up through

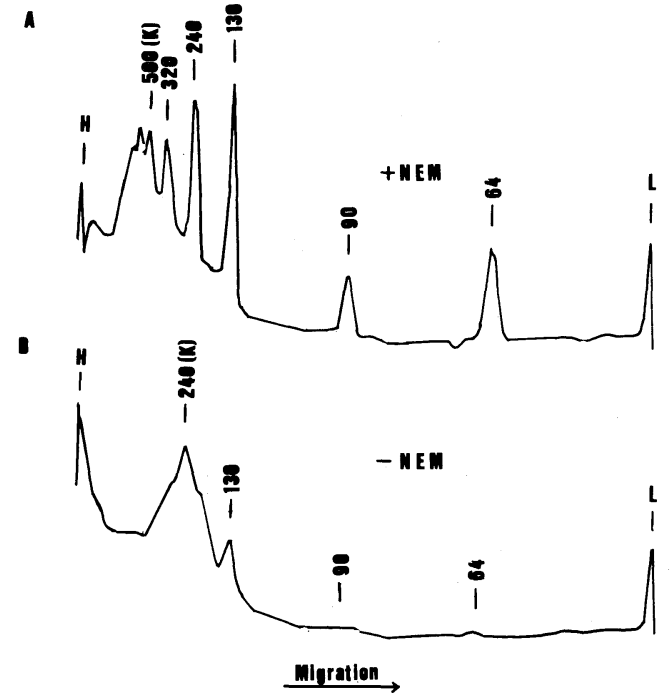

FIG. 1. SDS-PAGE of the Protein in PB-II Isolated from the Developing Endosperm of Rice Seeds.

PB-II was isolated from the developing endosperm of the rice seeds ( 10 days after anthesis) by the method described elsewhere. ${ }^{7)}$ PB-II was solubilized in SDS-urea solution with or without NEM. The proteins of PB-II were electrophoresed on a polyacrylamide concave gradient gel $(4 \sim 30 \%)$ as described in Materials AND Methods. (A) with $25 \mathrm{mM}$ NEM; (B), without NEM. Numbers represent molecular weights in kilos.

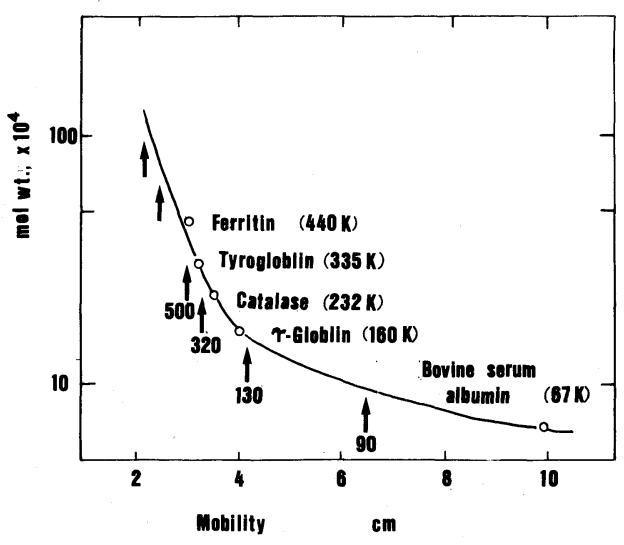

FIG. 2. Calibration Curve of the Gradient SDS-PAGE. Arrows indicate the positions of the glutelin bands in Fig. 1.

the assembly of the $64 \mathrm{k}$ primary unit in developing PB-II. Also Fig. 1 suggests that the assembled forms of the $64 \mathrm{k}$ polypeptide, such as the dimer $(130 \mathrm{k})$, tetramer $(240 \mathrm{k})$, 


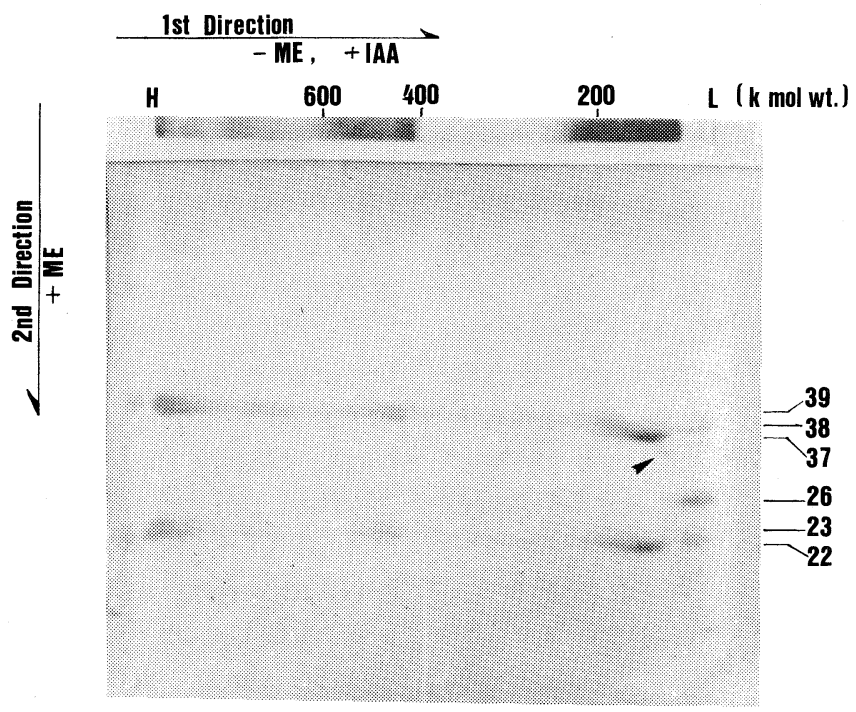

FIG. 3. Two-dimensional SDS-PAGE of the Proteins in PB-II of Developing Stage.

Isolated PB-II was solubilized in SDS-urea solution with $10 \mathrm{~mm}$ iodoacetic acid. The proteins in PB-II were electrophoresed in the 1 st direction on a $6 \%$ disc gel. After the 1 st gel electrophoresis, the gel was transferred onto a $13 \%$ slab gel and electrophoresed in the 2 nd direction. Migration was from left to right (1st dimension), then from top to bottom (2nd direction).

and hexamer $(320 \mathrm{k})$ are relatively stable. The fact that electrophoresis without NEM resulted in the increase in the $240 \mathrm{k}$ and high molecular weight polypeptides and a decrease in lower molecular weight polypeptides such as the 64,90 , and $130 \mathrm{k}$ proteins, indicates that glutelin, the storage protein of rice, is in the form of polymer in PB-II. Clearly, polymerization of glutein progresses stepwise through -S-S- disulfide linkages between polypeptides using the $64 \mathrm{k}$ protein as the primary unit.

Molecular weights and subunit composition of $P B-I I$

Proteins in PB-II were fractionated by their molecular weights with the SH- masking reagent using disc SDS-PAGE as the first dimension of electrophoresis, then in the second dimension with $\beta$-mercaptoethanol. By these procedures the subunit composition of the fractionated proteins (glutelins) with various molecular weights was clarified (Fig. 3). The formation of two bands in the two dimensional electrophoretograms indicated that the pro- teins in PB-II (glutelins) fell into two subunit groups. The subunit group with a higher molecular weight included at least two types of polypeptides, having similar molecular weights such as $38 \mathrm{k}$ and $39 \mathrm{k}$. Subunit groups with a lower molecular weight, however, included two polypeptides of $22 \mathrm{k}$ and $23 \mathrm{k}$. Protein of $64 \mathrm{k} \mathrm{mol}$. wt. in the first dimensional electrophoresis was composed of $37 \mathrm{k}$ and $22 \mathrm{k}$ polypeptides. The second dimensional PAGE under reducing conditions showed that the proteins electrophoresed to the gel front in the first dimensional PAGE contained $37 \mathrm{k}, 26 \mathrm{k}$, and $22 \mathrm{k}$ subunits. These results suggest that proglutelin (a $57 \mathrm{k}$ polypeptide) cleaves into the fragments of $37 \mathrm{k}$ and $22 \mathrm{k}$ subunits, which then might form the $64 \mathrm{k}$ protein. The $26 \mathrm{k}$ globulin is clearly a monomer or dimer without polymerization through $-\mathrm{S}-\mathrm{S}$ - linkages in PB-II. The polypeptide with the arrowhead appearing as a $35 \mathrm{k}$ protein seems to link with only the $64 \mathrm{k}$ polypeptide through $\mathrm{S}-\mathrm{S}$ interaction, but not with other higher molecular weight proteins. 


\section{DISCUSSION}

The major storage protein of rice (glutelin) accumulates specifically in the PB-II of the rice endosperm. Glutein in PB-II is synthesized first as a $57 \mathrm{k}$ polypeptide, and is then cleaved into two subunits. Then the subunits produced are polymerized and form high molecular weight glutelin. The details of the polymerization mechanism were not known. We found that the polymerization of glutelin progresses stepwise using the $64 \mathrm{k}$ protein as the primary unit (Fig. 1). The $57 \mathrm{k}$ polypeptide which is observed in the initial step of glutelin synthesis is cleaved into two subunits, $22 \mathrm{k}$ and $37 \mathrm{k}$. Then, the two subunits form a pair to create the $64 \mathrm{k}$ construction unit of a glutelin molecule. Thus the amino acid composition for the $64 \mathrm{k}$ polypeptide should be identical to that of the $57 \mathrm{k}$ precursor polypeptide.

One explanation for the difference in the apparent molecular weights between the two proteins is that the $57 \mathrm{k}$ polypeptide is a single chain polypeptide, but the $64 \mathrm{k}$ polypeptide is a protein which is formed by the pairing of a $22 \mathrm{k}$ and $37 \mathrm{k}$ chain. Therefore, the difference in the steric structure between $57 \mathrm{k}$ and $64 \mathrm{k}$ polypeptides may lead to the difference in their mobility in PAGE. Another explanation is that the $57 \mathrm{k}$ preçursor is modified by something such as glycosylation, during the change to the $64 \mathrm{k}$ storage form. Proteins with molecular weights of 130,240 , and $320 \mathrm{k}$ seem to be stable. They are thought to be dimers, tetramers, or hexamers of a $64 \mathrm{k}$ primary unit. The $320 \mathrm{k}$ protein is thought to continue further polymerization because a much higher molecular weight protein was observed in Fig. 1A. The $90 \mathrm{k}$ protein is difficult to consider as a polymer of the $64 \mathrm{k}$. This protein may be a transient form during the production of the $130 \mathrm{k}$ dimer from $64 \mathrm{k}$, with one more subunit, either $22 \mathrm{k}$ or $37 \mathrm{k}$, being added to the $64 \mathrm{k}$ unit. No subunits other than $22 \mathrm{k}$ or $37 \mathrm{k}$ contribute to form the $90 \mathrm{k}$ protein because only $22 \mathrm{k}$ and $37 \mathrm{k}$ are observed in the $90 \mathrm{k}$ protein (Fig. 3). Comparison of Fig. 1A and
B suggests that the formation of a high molecular weight glutein has a $64 \mathrm{k}$ protein as the starting unit, and the polymerization progressed through $\mathrm{S}-\mathrm{S}$ disulfide linkages. This is supported by the observation that in SDSPAGE without NEM, low molecular weight proteins decreased instead. A notable stability must be obtained in the form of $240 \mathrm{k}$, because a large amount of accumulation is observed at the position (Fig. 1B). Figure 3 shows clearly that rice glutelin is composed of two polypeptide groups as the fundamental unit. However, there seem to be a small diversity in the polypeptide composition between high molecular weight glutelin (larger than 240k) and lower molecular weight glutelins (smaller than $130 \mathrm{k}$ ). Gluteins smaller than $130 \mathrm{k}$ consist of $37 \mathrm{k}$ and $22 \mathrm{k}$ subunits, but glutelins larger than $240 \mathrm{k}$ are formed from combinations of $38 \mathrm{k}, 39 \mathrm{k}$, and $23 \mathrm{k}$ subunits.

Whether subunits which form high molecular weight glutelin differ originally from the ones which form low molecular weight glutein (64k) or whether the peptides used to form low molecular weight glutelin change during the formation of higher molecular weight glutelins remains to be examined.

PB-II seems to correspond to the crystalline type protein body described by Bechtel et al..$^{9)}$ Their observation was a reflection of the fact that the primary unit ( $64 \mathrm{k}$ protein) was highly organized during the build-up of the glutelin molecule. We demonstrated here that the chemical primary unit of glutelin is $64 \mathrm{k}$, but further studies are required to correlate the electron microscopically observed structure to the chemically observed molecular states.

\section{REFERENCES}

1) K. Kondo and Y. Morita, Bull. Res. Inst. Food Sci., Kyoto Univ., 15, 18 (1954).

2) H. Sawai, H. Nikaido and Y. Morita, Agric. Biol. Chem., 34, 1034 (1974).

3) H. Sawai and Y. Morita, Agric. Biol. Chem., 32, 496 (1970).

4) B. O. Juliano and D. Boulter, Phytochemistry, 15, 1601 (1976). 
5) H. Mitsuda, K. Murakami, T. Kusano and K. Yasumoto, Arch. Biochem. Biophys., 130, 678 (1969).

6) H. Mitsuda, K. Yasumoto, K. Murakami, T. Kusano and H. Kishida, Agric. Biol. Chem., 31, 293 (1967).
7) K. Tanaka, T. Sugimoto, M. Ogawa and Z. Kasai, Agric. Biol. Chem., 44, 1633 (1980).

8) U. K. Laemmli, Nature (London), 227, 680 (1970).

9) D. B. Bechtel and B. O. Juliano, Ann. Bot., 45, 503 (1980). 